Article

\title{
Pyrraline Formation Modulated by Sodium Chloride and Controlled by Encapsulation with Different Coating Materials in the Maillard Reaction
}

\author{
Zhili Liang ${ }^{1, *}$, Xu Chen ${ }^{2}$, Zhao Yang ${ }^{1}$, Yuzhu Lai ${ }^{1}$, Yinling Yang ${ }^{1}$, Chuying Lei ${ }^{1}$ and Ya Zeng ${ }^{1}$ \\ 1 School of Food Science, Guangdong Food and Drug Vocational College, Guangzhou 510520, China; \\ yangzhao19878@163.com (Z.Y.); laiyuzhuhu@icloud.com (Y.L.); yang114545@163.com (Y.Y.); \\ Lchuying1029@163.com (C.L.); Alina112697@163.com (Y.Z.) \\ 2 Engineering Research Center of Health Food Design \& Nutrition Regulation, School of Chemical \\ Engineering and Energy Technology, Dongguan University of Technology, Dongguan 523808, China; \\ chenxu@dgut.edu.cn \\ * Correspondence: zhililiang1988@gmail.com or liangzl@gdyzy.edu.cn; Tel.: +86-20-2916-4643
}

Received: 13 October 2019; Accepted: 7 November 2019; Published: 10 November 2019

\begin{abstract}
Advanced glycation end products (AGEs), which are present in heat-processed foods, have been associated with several chronic diseases. Sodium chloride $(\mathrm{NaCl})$ modulates the formation of furfurals and acrylamide in the Maillard reaction; however, the effects of $\mathrm{NaCl}$ on AGE formation are inconsistent. In this study, we investigated the effects of $\mathrm{NaCl}$ on pyrraline formation using glucose-lysine model systems. $\mathrm{NaCl}$, especially at $0.50 \%$, promoted Maillard browning and pyrraline formation, with a simultaneous increase in the 3-deoxyglucosone concentration. To reduce the rate of pyrraline formation, $\mathrm{NaCl}$ coated with different gums and starches were used. The results showed that $\mathrm{NaCl}$ encapsulation is an effective approach to mitigate pyrraline and 3-deoxyglucosone formation. The content of $\mathrm{NaCl}$ in the microparticles were $284 \pm 12,269 \pm 6,258 \pm 8,247 \pm 10,273 \pm 16$, and $288 \pm 15 \mathrm{mg} / \mathrm{g}$ (coated with waxy maize starch, normal maize starch, HYLON VII high amylose maize starch, gelatinized resistant starch, xanthan gum, and gum arabic, respectively). The heat resistance of the coating material was negatively correlated with the pyrraline and 3-deoxyglucosone formation, whereas the solubility of the coating material had the opposite results. Coating the material with gum had little effects on the reduction of pyrraline and 3-deoxyglucosone.
\end{abstract}

Keywords: encapsulation; sodium chloride; advanced glycation end products; starch; gum

\section{Introduction}

A non-enzymatic browning reaction (i.e., the Maillard reaction (MR)) in heat-processed foods begins between an amino acid and a reducing sugar, and is followed by a cascade of reactions. These reactions produce different intermediates, including aroma compounds and high molecular weight brown polymers [1]. In the food industry, desirable colors and aromas of foods (e.g., bread, meat, roasted nut, coffee, and confectionaries) are generated by MR during food processing. However, some compounds produced during MR are potentially harmful, including acrylamide, heterocyclic amines (HCAs), and advanced glycation end products (AGEs).

AGEs are modified-structure compounds produced in the late stage of MR. Dietary AGEs (d-AGEs) formation are rapidly stimulated by the heating temperature and time. AGEs have been associated with several chronic diseases, including diabetes [2,3] and kidney disorders [4-6]. In patients with diabetes, renal failure, overweight, or obesity, d-AGEs can modulate the AGE load in the body [7-9]. A high intake of d-AGEs may increase the risk of chronic diseases [10,11]; the restriction of d-AGEs can alleviate the burden of health risks associated with AGEs [12,13]. D-AGEs are generally associated with 
the glycation of lysine and arginine; however, lysine-derived AGEs, such as $\mathrm{N}^{\varepsilon}$-carboxymethyllysine $(\mathrm{CML}), \mathrm{N}^{\varepsilon}$ - carboxyethyllysine (CEL), and pyrraline, are generally used as d-AGE markers [14-16].

Pyrraline is one of the common AGEs, which has been be found predominantly in various food products after a high thermal impact. For example, up to $134 \mathrm{mg} / \mathrm{kg}$ protein pyrraline can be found in in processed carrot juice [17]. In bread crusts or rusks, the content of pyrraline can even range up to $3680 \mathrm{mg} / \mathrm{kg}$ protein [18]. 3-deoxyglucosone (3-DG), one of the major dicarbonyl compounds in the Maillard reaction, is a key intermediate in the pathway of pyrralline formation. As shown in Scheme 1, pyrraline is formed by the addition of 3-DG to the $\varepsilon$-amino group of lysine residues on proteins [19].

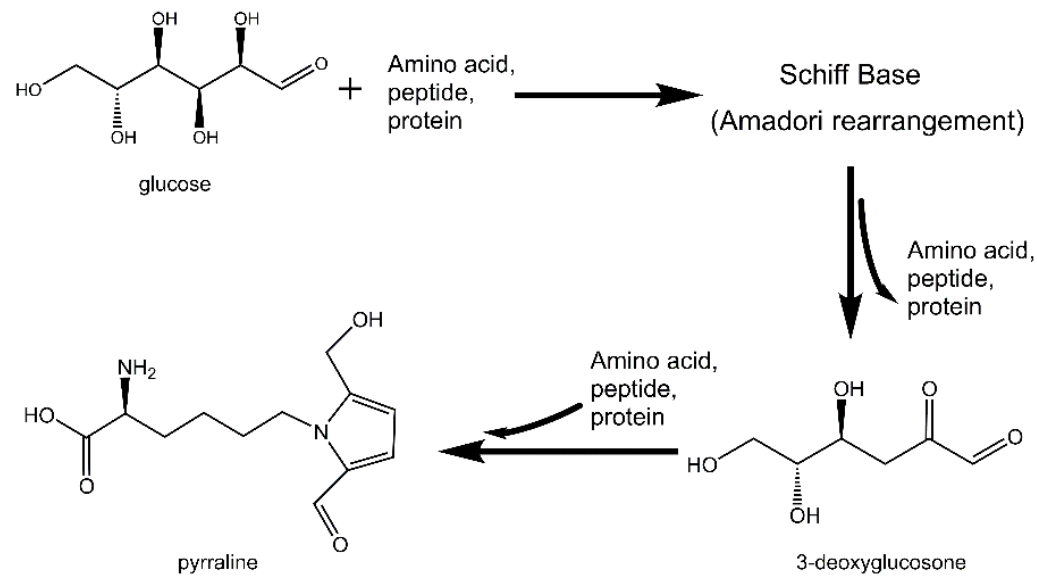

Scheme 1. The proposed pathway of pyrraline formation.

In the food industry, the reduction and/or prevention of d-AGEs formation is of the utmost importance. Monovalent, bivalent, and polyvalent cations, such as $\mathrm{Na}^{+}$and $\mathrm{Ca}^{2+}$, may affect $\mathrm{MR}$ through the dehydration of various key intermediates. For example, the addition of $\mathrm{Ca}^{2+}$ prevents acrylamide formation in an asparagine-glucose model system, but simultaneously boosts the formation of hydroxymethylfurfural (HMF) [20]. Levine et al. [21] reported that calcium chloride $\left(\mathrm{CaCl}_{2}\right)$ and sodium chloride $(\mathrm{NaCl})$ reduced acrylamide by $36 \%$ and $23 \%$, respectively, in a dough model system. However, Claus et al. [22] concluded that $\mathrm{NaCl}$ plays an inconsistent role in acrylamide formation -while the acrylamide concentration declined at $1-2 \% \mathrm{NaCl},>2 \% \mathrm{NaCl}$ increased acrylamide concentration. Similar results were obtained in an asparagine-glucose model system-acrylamide concentration declined with $0.5-5 \mu \mathrm{mol} / \mathrm{L} \mathrm{NaCl}$ and increased with $5-20 \mu \mathrm{mol} / \mathrm{L} \mathrm{NaCl}$ [20]. To prevent the HMF and acrylamide formation in food, researchers have evaluated the $\mathrm{NaCl}$ encapsulation. Fiore et al. [23] reported that lipid-coated $\mathrm{NaCl}$ can significantly prevent $\mathrm{HMF}$ formation in thermally processed foods. Therefore, in the food industry, the addition of $\mathrm{NaCl}$ can not only improve the sensory properties of foods by increasing the saltiness, texture, and other congruent flavor effects [24], but can also impact on the furfurals and acrylamide formations.

Even though there is considerable knowledge on the effect of $\mathrm{NaCl}$ on the furfurals and acrylamide formations during the heating of foods, there is little information on the effects of $\mathrm{NaCl}$ on d-AGE formation. We hypothesize that the $\mathrm{NaCl}$ concentration affects the AGE formation in MR. In this study, we evaluated the effect of $\mathrm{NaCl}$ on pyrraline formation using an established glucose-lysine model system. Additionally, we used $\mathrm{NaCl}$ coated with different gums and starches, and monitored the formation of pyrrraline and 3-DG at different heating temperatures and times.

\section{Materials and Methods}

In conventional cooking, the temperatures of the thermal-induced MR range between 100 and $30{ }^{\circ} \mathrm{C}$ [25]. Certain AGEs, such as CML and pyrraline, are likely to form at $120-200{ }^{\circ} \mathrm{C}$ [26-28]. Some studies [29-33] have reported that the sodium content (expressed as a percentage of mass concentration) ranges between $0.00 \%$ and $1.00 \%$ in foods, including packaged, commercially processed, and restaurant 
foods. Therefore, in this study, we used a temperature range of $140-180{ }^{\circ} \mathrm{C}$ and a sodium content of $0.00-1.00 \%$.

\subsection{Chemicals and Reagents}

All of the chemicals were of analytical grade, unless otherwise stated. The L-lysine, D-glucose, $\mathrm{NaCl}$, xanthan gum, and gum arabic were purchased from Macklin Biochemical Co., Ltd. (Shanghai, China). The acetonitrile and formic acid of HPLC grade were acquired from Merck (Darmstadt, Germany). A solid-phase extraction cartridge, Cleanert PEP-2 (200 mg/6 mL, Bonna-Agela Technologies Inc., Tianjin, China), was used for the purification of the MR products. The pyrraline (purity $>99.99 \%$ ) and 3-deoxyglucosone (purity $>99.99 \%$ ) were supplied by Toronto Research Chemicals (North York, Ontario, Canada). The starches were obtained from Ingredion Incorporated (Shanghai, China).

\subsection{Preparation of Glucose-Lysine-NaCl Model Systems}

A model system consisting of lysine, glucose, and $\mathrm{NaCl}$ was used to determine the effect of $\mathrm{NaCl}$ on pyrraline formation. Lysine $(0.1 \mathrm{mmol})$, glucose $(0.1 \mathrm{mmol})$, and $\mathrm{NaCl}$ (set concentration) were transferred to a 25-mL polytetrafluoroethylene (PTFE)-lined hydrothermal autoclave reactor (Tefic Biotech Co., Xi'an, China). The total reaction volume in the PTFE-lined tube was adjusted to $15 \mathrm{~mL}$, using deionized water. The final concentrations of $\mathrm{Na}^{+}$(not $\mathrm{NaCl}$ ) in the reaction solution were $0.00 \%$, $0.25 \%, 0.50 \%, 0.75 \%$, and $1.00 \%$. The concentration of $\mathrm{Na}^{+}$was $39.3 \%$ of the $\mathrm{NaCl}$ concentration. The tube was covered with a PTFE lid and inserted into the stainless-steel jacket, and the jacket was tightly sealed with a stainless-steel cap prior to the thermal treatments. The thermal treatments were performed in an oil bath at 140,160 , and $180^{\circ} \mathrm{C}$, for 5 to $20 \mathrm{~min}$. All of the reactions were performed in triplicate.

Following the thermal treatments, the autoclave reactors were immediately cooled to room temperature in an ice bath. Subsequently, $0.1 \mathrm{~mL}$ of a $5 \mathrm{~mol} / \mathrm{L}$ o-phenylenediamine (OPD) solution (dissolved in 1:1 methanol-water solution) was added to terminate the reaction, resulting in the derivatization of dicarbonyl compounds into azines (3-DG quinoxaline, abbreviated as 3-DG $\mathrm{qx}_{\text {) }}$ ), and shaken in the dark overnight. The mixture was passed through a $0.45-\mu \mathrm{m}$ membrane filter and stored at $-18{ }^{\circ} \mathrm{C}$ prior to the solid-phase extraction (SPE) and chromatographic analysis.

\subsection{Encapsulation Process}

Microencapsulation by spray-coating was performed using an YC-015 laboratory spray dryer (Shanghai Pilotech Instrument and Equipment Co., Shanghai, China). The NaCl was coated with six different materials, namely: xanthan gum (XG), gum arabic (GA), waxy maize starch (WMS), normal maize starch (NMS), HYLON VII high amylose maize starch (HAMS), and gelatinized resistant starch (GRS).

The sprayed liquid was prepared using a coating material, $\mathrm{NaCl}$, and deionized water. The $\mathrm{NaCl}$ $(1 \mathrm{~g})$ and coating material $(10 \mathrm{~g})$ were mixed, added to $1 \mathrm{~L}$ deionized water, and heated to gelatinization under constant stirring. A two-fluid nozzle with a cap orifice diameter of $0.7 \mathrm{~mm}$ was used. The processing conditions consisted of a drying air inlet temperature of $200{ }^{\circ} \mathrm{C}$, a drying air outlet temperature of $80^{\circ} \mathrm{C}$, a liquid feed volumetric flow rate of $15 \mathrm{~mL} / \mathrm{min}$, an air volumetric flow pressure of $0.25 \mathrm{MPa}$, and a drying air volumetric flow rate of $60 \mathrm{~L} / \mathrm{h}$. After the completion of the experiment and when the air inlet temperature was $<60^{\circ} \mathrm{C}$, the samples were collected from the product collection vessel.

\subsection{Thermal Properties of $\mathrm{NaCl}$ Microparticles}

The melting points of the $\mathrm{NaCl}$ microparticles were measured using a differential scanning calorimeter (DSC; DSC 3, Mettler Toledo, Zurich, Switzerland), previously calibrated with indium $\left(\mathrm{mp}=156.6^{\circ} \mathrm{C}, \Delta H=28.5 \mathrm{~J} / \mathrm{g}\right)$. The analysis was performed in duplicate in a nitrogen gas atmosphere (30 mL/min), using an empty pan as reference. The samples ( $20 \mathrm{mg}$; dry starch or gum basis) in deionized water $\left(3 \times, w / w\right.$; dry starch or gum basis) were scanned from $30^{\circ} \mathrm{C}$ to $180{ }^{\circ} \mathrm{C}$ at $10{ }^{\circ} \mathrm{C} / \mathrm{min}$ in 
a sealed aluminum pan. The onset temperature $\left(T_{o}\right)$, peak temperature $\left(T_{p}\right)$, conclusion temperature $\left(T_{c}\right)$, and enthalpy change $(\Delta H)$ were determined. Following the first scan, the sealed aluminum pan was placed at $4{ }^{\circ} \mathrm{C}$ for $7 \mathrm{~d}$ for the retrogradation analysis.

\subsection{Physical Analysis of the Microparticles}

\subsubsection{Particle Size Distribution}

The microparticle size distributions were determined in triplicate by laser granulometry (Malvern Mastersizer 2000, Malvern, United Kingdom).

\subsubsection{Scanning Electron Microscopy (SEM)}

The microparticles were mounted on aluminum stubs with double-sided sticky carbon tape, and sputter-coated with a fine layer of gold (metallization step). The pressure was set to $10^{-3} \mathrm{mPa}$ during the metallization step, and to $6 \times 10^{-6} \mathrm{mPa}$ inside the apparatus. The morphology of the microparticles was examined using a Zeiss EVO18 SEM instrument (Carl Zeiss, Oberkochen, Germany) operated at a $5 \mathrm{KV}$ accelerating voltage.

\subsubsection{Content of $\mathrm{NaCl}$ in Microparticles}

An inductively coupled plasma-optical emission spectrometer (ICP-OES, model Optima 7000 DV, PerkinElmer Inc., Boston, MA, USA) with a radial plasma configuration was used to determine the content of the sodium ions. Standard plasma conditions were used (i.e., $1300 \mathrm{~W}$ for radio-frequency power; $1.5 \mathrm{~mL} / \mathrm{min}$ pump rate; and $15.0,0.2$, and $0.8 \mathrm{~L} / \mathrm{min}$ for the plasma, auxiliary, and nebulizer gas flow, respectively). The detection wavelength for sodium was $589.592 \mathrm{~nm}$.

The microparticles $(0.2 \mathrm{~g})$ were transferred to a $25-\mathrm{mL}$ PTFE tube and mixed with $10 \mathrm{~mL}$ of $65 \%$ nitric acid. The mixture was shaken and covered with a PTFE lid prior to overnight storage inside a fume hood. The tube was placed in a graphite oven and pyrolyzed for $1 \mathrm{~h}$ at $100^{\circ} \mathrm{C}$ with the lid, $2 \mathrm{~h}$ at $150{ }^{\circ} \mathrm{C}$ without the lid, $1 \mathrm{~h}$ at $170^{\circ} \mathrm{C}$ without the lid, and $10 \mathrm{~min}$ at $170^{\circ} \mathrm{C}$ with the lid. After pyrolysis, a colorless and transparent solution was obtained. The solution was transferred to a 50-mL volumetric flask with $1 \%$ nitric acid, and the volume of the solution was adjusted to $50 \mathrm{~mL}$ with $1 \%$ nitric acid. Finally, $0.5 \mathrm{~mL}$ of the solution was diluted to $1 \mathrm{~L}$ with $1 \%$ nitric acid, prior to analysis in the ICP-OES. The solutions used for the standard curves ranged from 0 to $10 \mathrm{mg} / \mathrm{L}$ of $\mathrm{NaCl}$. A standard solution of $\mathrm{NaCl}$ was prepared from a $1 \mathrm{mg} / \mathrm{mL}$ stock solution in $1 \%$ hydrochloric acid (Merck, Kenilworth, NJ, USA).

\subsubsection{Conductimetry}

The conductivity experiments were carried out using two different devices. The $\mathrm{NaCl}$ content was measured using a digital conductivity meter (DDS-307A, INESA Scientific Instrument Co., Shanghai, China) equipped with a DJS-1C probe (INESA Scientific Instrument Co., Shanghai, China). The microparticles were dispersed in deionized water, and crushed prior to titration. The $\mathrm{NaCl}$ cumulative release in deionized water was monitored with a T50 titrator equipped with an Inlab 730 probe and an internal agitation system (Mettler Toldeo, Shanghai, China). The microparticles were loaded into the conductimeter cell containing $80 \mathrm{~mL}$ of deionized water. The release of $\mathrm{NaCl}$ was monitored over $20 \mathrm{~min}$ under agitation. All of the measurements were performed in triplicate.

\subsection{Preparation of Glucose-Lysine-Microparticle Model Systems}

A model system consisting of lysine, glucose, and $\mathrm{NaCl}$ microparticles was used to assess the efficacy of the encapsulation in modulating pyrraline formation. The model systems were prepared, as previously described for the glucose-lysine- $\mathrm{NaCl}$ model systems, with a few modification. The details of all of the formulations are shown in Table 1. Briefly, $0.1 \mathrm{mmol}$ lysine, $0.1 \mathrm{mmol}$ glucose, and $\mathrm{NaCl}$ microparticles (set concentration) were transferred to a 25-mL PTFE tube. The total reaction 
volume was adjusted to $15 \mathrm{~mL}$ using deionized water. The final concentration of $\mathrm{Na}^{+}$(not $\mathrm{NaCl}$ ) in the reaction solution was set to $0.50 \%$. The thermal treatments were performed in an oil bath at $140{ }^{\circ} \mathrm{C}$ for $20 \mathrm{~min}$. All of the reactions were performed in triplicate. The following procedures of derivatization were performed according to the previous procedures in Section 2.2.

Table 1. The formulations used to prepare the model systems in a PTFE-lined tube ${ }^{\text {a. }}$

\begin{tabular}{|c|c|c|c|}
\hline Setup & \multicolumn{3}{|c|}{ Amount in the PTFE Lined Tube (mg) } \\
\hline $\mathrm{NaCl} 0.000 \%\left(\mathrm{Na}^{+} 0.00 \%\right)$ & 0 & & \\
\hline $\mathrm{NaCl} 1.250 \%\left(\mathrm{Na}^{+} 0.50 \%\right)$ & 188 & & \\
\hline $\mathrm{NaCl} 1.875 \%\left(\mathrm{Na}^{+} 0.75 \%\right)$ & 281 & & \\
\hline blank microparticle (WMS) + NaCl & 188 & & 474 \\
\hline blank microparticle (WMS) & & & 474 \\
\hline encapsulated $\mathrm{NaCl}$ (NMS) & & 699 & \\
\hline blank microparticle (NMS) $+\mathrm{NaCl}$ & 188 & & 511 \\
\hline blank microparticle (NMS) & & & 511 \\
\hline encapsulated $\mathrm{NaCl}$ (HAMS) & & 729 & \\
\hline blank microparticle (GRS) $+\mathrm{NaCl}$ & 188 & & 573 \\
\hline blank microparticle (GRS) & & & 573 \\
\hline encapsulated $\mathrm{NaCl}(\mathrm{XG})$ & & 689 & \\
\hline blank microparticle $(X G)+\mathrm{NaCl}$ & 188 & & 501 \\
\hline blank microparticle (XG) & & & 501 \\
\hline encapsulated $\mathrm{NaCl}$ (GA) & & 653 & \\
\hline blank microparticle (GA) $+\mathrm{NaCl}$ & 188 & & 465 \\
\hline blank microparticle (GA) & & & 465 \\
\hline
\end{tabular}

${ }^{a}$ The following components were common for all of the formulations: glucose, $0.018 \mathrm{~g}$; lysine, $0.015 \mathrm{~g}$; and deionized water, $15 \mathrm{~g}$. The data of the $\mathrm{NaCl}$ and coating materials were based on the results of Section 2.5.3. PTFE-polytetrafluoroethylene; WMS—-waxy maize starch; NMS—normal maize starch; HAMS-HYLON VII high amylose maize starch; GRS—gelatinized resistant starch; XG—xanthan gum; GA—gum arabic.

\subsection{Extent of Browning}

The extent of browning in the model systems was assessed with a TU-1810 UV/VIS spectrophotometer (Beijing Puxi Instrument Co., Beijing, China) at $420 \mathrm{~nm}$, following appropriate dilutions. The color intensities of the samples were presented as absorbance values after multiplication with the dilution factor.

\subsection{Pyrraline and 3-DG Analysis}

\subsubsection{Solid Phase Extraction (SPE) Procedures}

The sample purification was performed by the SPE procedures, according to our previous study [27].

\subsubsection{LC-MS Analysis}

The pyrraline and 3-DG were analyzed by LC-MS, according to our previous study, with some modifications [27]. Briefly, pyrraline was quantified by its molecular ion peak $(m / z=255.13)$, and 3-DG was determined by the molecular ion peak of $3-\mathrm{DG}_{\mathrm{qx}}(\mathrm{m} / z=235.10)$. The monitoring time was $15 \mathrm{~min}$. An external calibration was performed with standards.

\subsection{Statistical Analysis}

The statistically significant differences among the means from the triplicate analyses $(p<0.05)$ were determined by Duncan's multiple range test using SPSS (version 12.0 for Windows, SPSS Inc., Chicago, IL, USA). 


\section{Results and Discussion}

\subsection{Effect of $\mathrm{NaCl}$ in Glucose-Lysine-NaCl Model Systems}

\subsubsection{Effect of $\mathrm{NaCl}$ on the Browning Intensity}

Figure S1 (see Supplementary Materials) shows the browning development with $0.00 \%$ to $1.00 \%$ $\mathrm{Na}^{+}$at $140-180{ }^{\circ} \mathrm{C}$ in glucose-lysine- $\mathrm{NaCl}$ model systems. Figure S2 (see Supplementary Materials) shows the browning development with heating time. The findings revealed that with the increasing temperature and heating time, the browning intensity increased. This conclusion is partially confirmed by the absorbance results at $420 \mathrm{~nm}$ (Figure 1 ). MR has a relatively high temperature coefficient $\left(Q_{10}\right.$ values range between 2 and 8) [34]; therefore, the heating temperatures can significantly accelerate the MR.

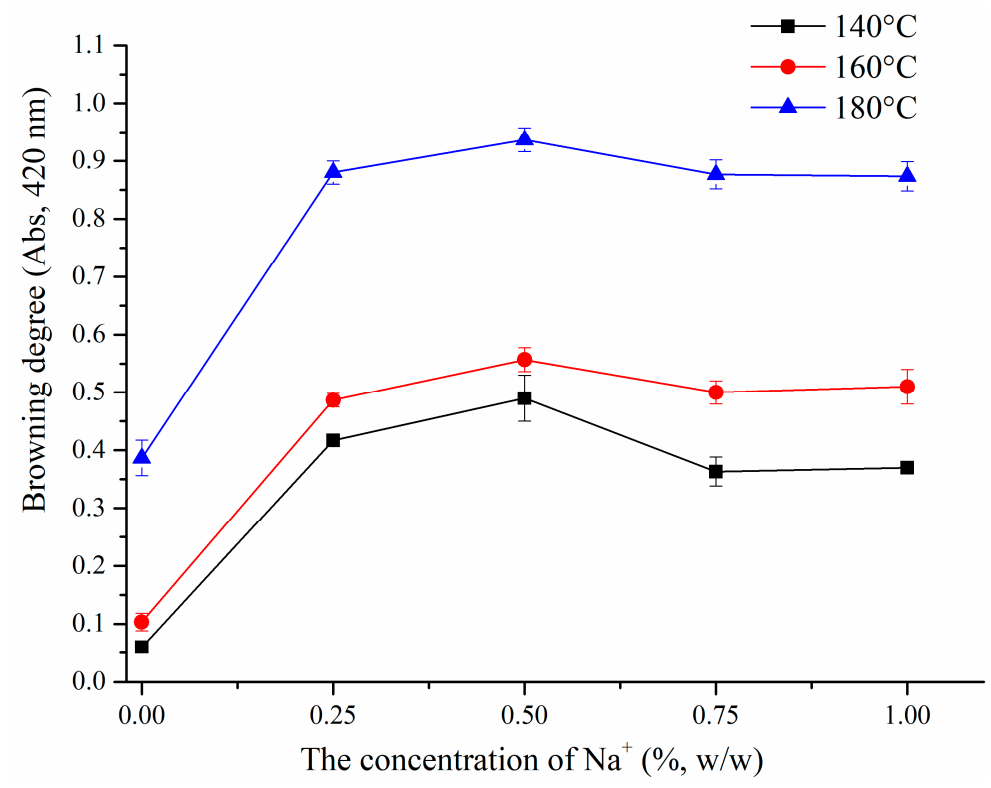

Figure 1. Browning intensity $(\lambda=420 \mathrm{~nm})$ at different sodium concentrations in model reaction systems.

However, an interesting trend occurred in the browning intensity when we investigated the effect of $\mathrm{NaCl}$. Figure S1 (see Supplementary Materials) shows that the browning development does not accelerate continuously with an increase in $\mathrm{Na}^{+}$content. The curves in Figure 1 show that the maximum browning intensity occurred at $0.50 \% \mathrm{Na}^{+}$in all of the heating treatments. At 140, 160, and $180{ }^{\circ} \mathrm{C}$, the color intensity of the MR products was $8.2,5.6$, and 2.4 times higher, respectively, at $0.50 \%$ $\mathrm{Na}^{+}$than at $0.00 \% \mathrm{Na}^{+}$. In addition, browning intensity increased significantly from 0.00 to $0.25 \%$ $\mathrm{Na}^{+}$and increased slowly from 0.25 to $0.50 \% \mathrm{Na}^{+}$. At $>0.50 \% \mathrm{Na}^{+}$, the browning intensity gradually decreased. These results were partially consistent with the results reported by Kwak [35]. The color intensity of the MR products was enhanced by $~ 5 \%$ with $1 \% \mathrm{NaCl}$ (i.e., $0.4 \% \mathrm{Na}^{+}$) and inhibited by $20 \%$ with $10 \% \mathrm{NaCl}$ (i.e., $4 \% \mathrm{Na}^{+}$). However, in this study, the $0.25-1.00 \% \mathrm{Na}^{+}$enhanced the browning of the MR products heated at 140 to $180{ }^{\circ} \mathrm{C}$ for 20 min compared with $0.00 \% \mathrm{Na}^{+}$. The main reason for this difference may be the low $\mathrm{Na}^{+}$and the absence of the phosphate buffer in our study. Compared to the study by Kwak, our study used high temperature and short time heating treatments.

The effect of $\mathrm{Na}^{+}$on the Maillard browning appears to be quite intricate, because there are contradictory reports in the literature. A high $\mathrm{NaCl}$ increased the browning in the cereal model systems $\left(\mathrm{Na}^{+}\right.$at $0 \%$ to $2.14 \%$ ) [36] and in the breakfast cereals $\left(\mathrm{Na}^{+}\right.$at $0 \%$ to $2.18 \%$ ) [37]. Moreau el al. reported that the browning intensity promoted by $\mathrm{NaCl}$ is neither related to the $\mathrm{NaCl}$ hygroscopic behavior, nor to the physical state of the model systems (glassy vs rubbery) [36]. In addition, Rizzi observed that $\mathrm{NaCl}\left(0.04 \mathrm{M}, \sim\right.$ mass \% of $\mathrm{Na}^{+}$at $\left.0.1 \%\right)$ increased the Maillard browning in aqueous $\mathrm{pH}$ 7.2-buffered 
(bis/tris) solutions of a ribose-glycine system [38]. However, Kwak and Lim concluded that the Maillard browning can be greatly inhibited by the high $\mathrm{NaCl}$ concentrations (e.g., $1 \%$ or $10 \%$; mass percent of $\mathrm{Na}^{+}$at either $0.4 \%$ or $4 \%$ ) in aqueous binary mixtures of glucose and different amino acids in a $\mathrm{pH} 6.5$ citrate-phosphate buffer heated at $100{ }^{\circ} \mathrm{C}$ for $6 \mathrm{~h}$ [35]. Similarly, a $5 \%$ or $10 \% \mathrm{NaCl}\left(\mathrm{mass} \%\right.$ of $\mathrm{Na}^{+}$at $2 \%$ or $4 \%$ ) can weaken the Maillard browning in aqueous binary mixtures of glucose, and in different amino acids in a citrate or phosphate buffer heated at $100{ }^{\circ} \mathrm{C}$ after $60 \mathrm{~min}$ [39]. These differences may be attributed to the role of the phosphate buffer solutions in the mixtures. The phosphate anion enhances the Maillard browning by providing reactive intermediates directly from sugars [40,41].

With respect to the enhancement of the Maillard browning by $\mathrm{NaCl}$, the evidence suggests that the $\mathrm{NaCl}$ addition promotes the interconversion of glucose-fructose and the accumulation of 1-deoxyglucosone (1-DG) and 3-DG [42], which can increase the browning intensity during the final stage of MR. This evidence will be further discussed in the section on 3-DG formation.

\subsubsection{Effect of $\mathrm{NaCl}$ on Pyrraline Formation}

Figure 2 shows the pyrraline concentrations at different $\mathrm{Na}^{+}$levels. The maximum pyrraline concentrations $\left(252.90 \pm 0.36 \mu \mathrm{mol} / \mathrm{mol}\right.$ lysine at $140{ }^{\circ} \mathrm{C}, 248.63 \pm 0.66 \mu \mathrm{mol} / \mathrm{mol}$ lysine at $160{ }^{\circ} \mathrm{C}$, and $217.13 \pm 2.31 \mu \mathrm{mol} / \mathrm{mol}$ lysine at $180{ }^{\circ} \mathrm{C}$ ) were obtained at $0.50 \% \mathrm{Na}^{+}$. At $0.00-0.25 \% \mathrm{Na}^{+}$, the pyrraline content increased rapidly $\left(104.81 \pm 3.03\right.$ to $224.76 \pm 1.55 \mu \mathrm{mol} / \mathrm{mol}$ lysine at $140{ }^{\circ} \mathrm{C}, 113.68 \pm 2.65$ to $217.38 \pm 1.72 \mu \mathrm{mol} / \mathrm{mol}$ lysine at $160{ }^{\circ} \mathrm{C}$, and $124.79 \pm 2.02$ to $202.15 \pm 0.39 \mu \mathrm{mol} / \mathrm{mol}$ lysine at $180{ }^{\circ} \mathrm{C}$ ) in each temperature group. The pyrraline concentration continued to increase at $0.25-0.50 \% \mathrm{Na}^{+}$. However, at $>0.50 \% \mathrm{Na}^{+}$, the pyrraline concentration decreased gradually. In this study, the maximum pyrraline concentration was obtained at $140{ }^{\circ} \mathrm{C}$, consistent with our past findings $[27,28]$.

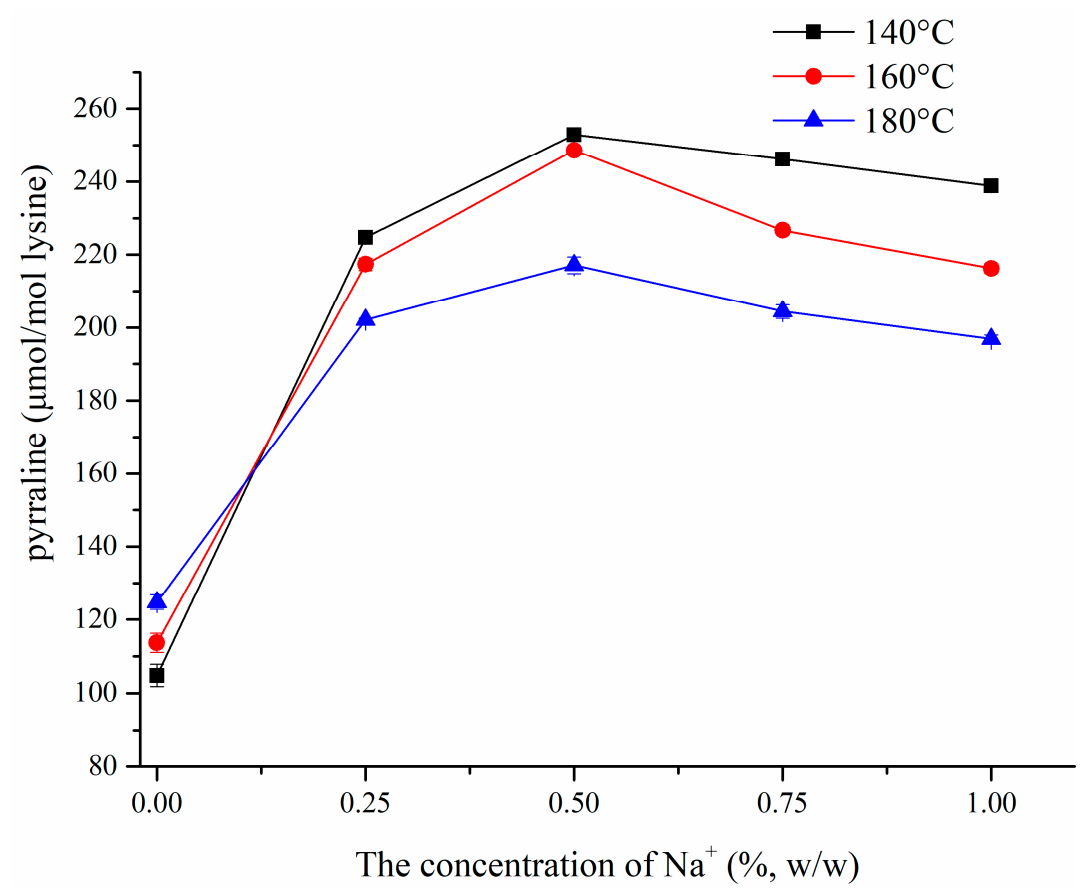

Figure 2. Sodium and temperature-dependent formation of pyrraline in model reaction systems.

The results obtained from acrylamide, a food contaminant derived from MR, were different to the pyrraline results. Levine and Ryan found that the acrylamide formation in a dough model with $0.02 \mathrm{M}$ $\mathrm{NaCl}$ (mass \% of $\mathrm{Na}^{+}$at $\sim 0.02 \%$ based on the dough weight) did not differ from the control $\left(0 \% \mathrm{Na}^{+}\right)$, while $0.04 \mathrm{M}\left(\sim 0.04 \% \mathrm{Na}^{+}\right)$and $0.08 \mathrm{M}\left(\sim 0.07 \% \mathrm{Na}^{+}\right) \mathrm{NaCl}$ significantly reduced the acrylamide content by $\sim 23 \%$ [21]. Unexpectedly, the increase in $\mathrm{NaCl}$ from $0.08 \mathrm{M}\left(\sim 0.07 \% \mathrm{Na}^{+}\right)$to $0.44 \mathrm{M}\left(\sim 0.40 \% \mathrm{Na}^{+}\right)$ had insignificant effects on the acrylamide formation. However, some studies have reported that the 
acrylamide formation can be reduced by $1 \%$ to $2 \% \mathrm{NaCl}\left(0.4\right.$ to $\left.0.8 \% \mathrm{Na}^{+}\right)$in bread and roll production at $220{ }^{\circ} \mathrm{C}$ for $30 \mathrm{~min}$ [22], and by $1.3 \% \mathrm{NaCl}\left(0.52 \% \mathrm{Na}^{+}\right)$in a cracker model baked at $180{ }^{\circ} \mathrm{C}$ for $15 \mathrm{~min}$ [43]. The differing effects of $\mathrm{NaCl}$ on pyrraline and acrylamide formation can be attributed to the following three aspects. First, acrylamide formation occurs at relatively high temperatures (up to $220^{\circ} \mathrm{C}$ ) with dry heat treatment, whereas pyrraline was produced at $120-180{ }^{\circ} \mathrm{C}$ with humid heat in our study. Second, acrylamide is formed predominantly by sugars reacting with asparagine, while pyrraline is mainly formed from sugars reacting with lysine. Third, the dough and cracker models [21,43] are more complex than the simplified models used in our study.

In MR, pyrraline is formed from 3-DG between a reducing sugar and the epsilon-amino group of lysine [44]. The effect of $\mathrm{NaCl}$ on pyrraline formation may be linked to changes in the pyrraline formation pathway. Hodge [45] classified MR into the following three stages: initial, intermediate, and final stages. During the initial stage, sugar-amine condensation and Amadori rearrangement occur, resulting in Amadori rearrangement products without absorption in the ultraviolet region. During the intermediate stage, complex reactions involving sugar dehydration, fragmentation, and amino acid degradation (Strecker degradation) occur, with a strong absorption in the ultraviolet region. During the final stage, highly colored products are formed via aldol condensation, aldehyde-amine condensation, and heterocyclic nitrogen compound synthesis. Therefore, it is possible that $\mathrm{NaCl}$ alters these complex reactions.

Sugar dehydration and fragmentation are affected by $\mathrm{Na}^{+}$; this will be discussed in the following section. The isomerization of glucose into fructose, which can occur in MR [28], facilitates pyrraline formation, because of the high reactivity of fructose [27]. In addition, $\mathrm{NaCl}$ may promote a constant isomerization rate [46]. The interaction of $\mathrm{NaCl}$ with glucose catalyzes the mutarotation and isomerization of glucose into fructose [47]. The sugar-metal coordination is responsible for the reaction; the metal interacts with the hemiacetal portion of glucopyranose [47]. $\mathrm{Na}^{+}$may increase the rate constants, especially with the transition states in a particular stereochemistry, of the dehydration of the intact fructofuranose ring [48].

\subsubsection{Effect of $\mathrm{NaCl}$ on 3-DG Formation}

Figure 3 shows that the 3 -DG concentration increased $(0.38 \pm 0.09$ to $5.29 \pm 0.04 \mathrm{mmol} / \mathrm{mol}$ glucose at $140{ }^{\circ} \mathrm{C}$ and $0.52 \pm 0.07$ to $4.61 \pm 0.08 \mathrm{mmol} / \mathrm{mol}$ glucose at $180{ }^{\circ} \mathrm{C}$ ) from $0.00 \%$ to $0.50 \% \mathrm{Na}^{+}$. However, a slight rise in 3-DG concentration $(0.42 \pm 0.05$ to $1.43 \pm 0.14 \mathrm{mmol} / \mathrm{mol}$ glucose $)$ was observed, from $0.00 \%$ to $0.50 \% \mathrm{Na}^{+}$at $160{ }^{\circ} \mathrm{C}$. At $>0.50 \% \mathrm{Na}^{+}$, the 3-DG concentration gradually decreased in each temperature group. In general, the changes in the 3-DG (Figure 3) were consistent with the changes in pyrraline (Figure 2) at the same temperature, except for at $160{ }^{\circ} \mathrm{C}$. The exception can be because some other nitrogen compounds derived from 3-DG may be produced easier than pyrraline at $160{ }^{\circ} \mathrm{C}$ [49].

3-DG is the key intermediate in pyrraline formation; therefore, $\mathrm{NaCl}$ may affect pyrraline formation by modifying the sugar dehydration and fragmentation. As aforementioned, sugar dehydration and fragmentation mainly occur during the intermediate stage of $\mathrm{MR}$. In this stage, $\mathrm{Na}^{+}$forms complexes with carbohydrate or intermediates to stabilize a particular conformation that facilitates ring opening during the process of dehydration and fragmentation [50]. Furthermore, computational evidence suggests that $\mathrm{Na}^{+}$directly interacts with nucleophilic oxygen molecules [51], which are central during carbohydrate pyrolysis, dehydration, and isomerization [48]. In fact, 1, 2-dehydration reactions of open D-glucose to dicarbonyl compounds, and 1, 2-dehydration reactions of $\beta$-D-glucose to cyclic enols may be catalyzed in the presence of $\mathrm{Na}^{+}$[48]. The former is involved in 3-DG formation and exerts a powerful effect on the pyrraline formation pathway, and the latter contributes to 5-hydroxymethylfurfural (5-HMF) formation. Consequently, these computational results may be partly responsible for the acceleration of 3-DG formation with $\mathrm{NaCl}$. In this study, 3-DG gradually decreased at $\mathrm{Na}^{+}>0.50 \%$ (Figure 3). This result suggests that the 1,2-dehydration reactions of $\beta$-D-glucose to cyclic enols may be strengthened, whereas the 1,2-dehydration reactions of open D-glucose to dicarbonyl compounds may be weakened. 


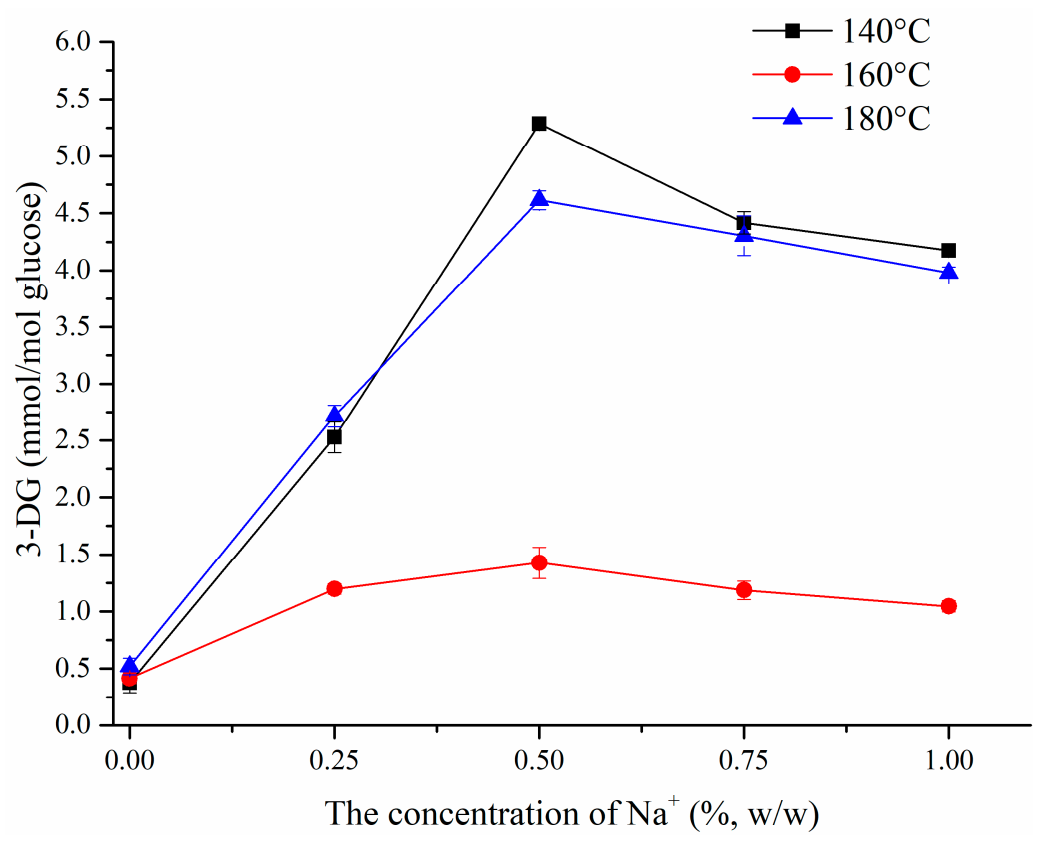

Figure 3. Sodium and temperature-dependent formation of 3-DG in model reaction systems.

However, the evidence has shown that the formation of 3-DG, which is the dominant component of $\alpha$-dicarbonyl compounds, decreased in the presence of $\mathrm{NaCl}\left(\sim\right.$ mass $\%$ of $\mathrm{Na}^{+}$at $0.23 \%$ ) [46]. The presence of $1.5 \% \mathrm{NaCl}\left(\sim 0.6 \% \mathrm{Na}^{+}\right)$had no effect on the formation of $\alpha$-dicarbonyl compounds [42]. These inconsistent results may be attributed to the dominant role of 1,2-dehydration reactions of $\beta$-D-glucose into cyclic enols during sugar dehydration and fragmentation.

In summary, the results revealed that $\mathrm{NaCl}$ plays a dual role in 3-DG formation during sugar dehydration and fragmentation. A low $\mathrm{Na}^{+}(<0.50 \%)$ facilitates 3-DG formation in MR, whereas a high $\mathrm{Na}^{+}(>0.50 \%)$ impedes 3-DG formation. It has been proposed that $\mathrm{Na}^{+}$changes the reaction rate coefficients of glucose pyrolysis to varying degrees, with approximately $70 \%$ of the reactions being promoted by $\mathrm{Na}^{+}$, approximately $25 \%$ of the reactions being inhibited by $\mathrm{Na}^{+}$, and the rest not being affected [48]. Moreover, the effect of salt on the rate constants of $\alpha$-dicarbonyl compound formation varies with the precursor, compounds, and temperature [46].

\section{2. $\mathrm{NaCl}$ Encapsulation Modulates Pyrraline Formation}

Past studies on $\mathrm{NaCl}$ encapsulation assessed the release of oil electrolytes (e.g., canola oil and triglycerides) in water emulsion systems [52,53]. Lipid-coated $\mathrm{NaCl}$ reduced the 5-HMF and acrylamide formation in MR [23]. However, the use of $\mathrm{NaCl}$ encapsulation to modulate AGEs formation has never evaluated.

$\mathrm{NaCl}$ can be successfully encapsulated using spray coating. Microparticles with mean diameters of $789,866,773,766,780$, and $795 \mu \mathrm{m}$ were obtained for $\mathrm{NaCl}$ coated with WMS, NMS, HAMS, GRS, $X \mathrm{G}$, and GA, respectively (Table 2). The $\mathrm{NaCl}$ content was measured by the conductimetry and titrated at $284 \pm 12,269 \pm 6,258 \pm 8,247 \pm 10,273 \pm 16$, and $288 \pm 15 \mathrm{mg} / \mathrm{g}$ of microparticles (coated with WMS, NMS, HAMS, GRS, XG, and GA, respectively). The $\mathrm{NaCl}$ content in the microparticles provided an important basis for the formulation design (Table 1). 
Table 2. Particle size distribution of NaCl-coated microparticles (sieving mesh sizes no. 100) ${ }^{a}$.

\begin{tabular}{lc}
\hline \multicolumn{1}{c}{ Sample } & $\mathbf{D}_{\mathbf{3 , 2} \mathbf{2}}(\boldsymbol{\mu m})$ \\
\hline $\mathrm{NaCl}$ coated by WMS & 789 \\
$\mathrm{NaCl}$ coated by NMS & 866 \\
$\mathrm{NaCl}$ coated by HAMS & 773 \\
$\mathrm{NaCl}$ coated by GRS & 766 \\
$\mathrm{NaCl}$ coated by $\mathrm{XG}$ & 780 \\
$\mathrm{NaCl}$ coated by GA & 795 \\
\hline
\end{tabular}

a WMS - waxy maize starch; NMS—normal maize starch; HAMS-HYLON VII high amylose maize starch; GRS—gelatinized resistant starch; XG—xanthan gum; GA—gum arabic.

\subsubsection{Thermal (DSC) Properties of $\mathrm{NaCl}$ Microparticles}

The DSC thermograms of the $\mathrm{NaCl}$ microparticles are shown in Figure S3-S8 (see Supplementary Materials). For the starch-based coating materials, the peak in the DSC thermograms can be attributed to the dissociation in the double helix of amylopectin [54]. XG is a polysaccharide with a linear and branched chain structure [55], and GA is a mixture of glycoproteins and polysaccharides with branched chains [56]. Therefore, gums with structures similar to starch-based coating materials may result in the peak in the DSC thermograms of XG and GA.

The transition temperatures, onset $\left(T_{o}\right)$, peak $\left(T_{p}\right)$, conclusion $\left(T_{c}\right)$, and enthalpy change $(\Delta H)$ are presented in Table 3. In the starch- and gum-coated microparticles, the transition temperatures had the following order: GA-coated $\mathrm{NaCl} \approx$ WMS-coated $\mathrm{NaCl}<$ NMS-coated $\mathrm{NaCl}<$ HAMS-coated $\mathrm{NaCl}$ $<$ GRS-coated $\mathrm{NaCl} \approx$ XG-coated $\mathrm{NaCl}$. In the starch-coated microparticles, this result is caused by the content of amylose and amylopectin. A high amylose content and low amylopectin content can result in high transition temperatures of starch. In the gum-coated microparticles, the structure and content of the polysaccharides in the gum may lead to different transition temperatures. It can be hypothesized that the coated $\mathrm{NaCl}$ microparticles with a high transition temperature may exhibit a high heat resistance, thereby allowing for a slow release rate of $\mathrm{NaCl}$.

Table 3. Thermal properties of $\mathrm{NaCl}$-coated microparticles treated with heat moisture and annealing ${ }^{\mathrm{a}}$.

\begin{tabular}{lccccc}
\hline \multirow{2}{*}{ Samples } & \multicolumn{5}{c}{ Gelatinization of Coating Materials } \\
\cline { 2 - 6 } & $\boldsymbol{T}_{\boldsymbol{o}}\left({ }^{\circ} \mathbf{C}\right)$ & $\boldsymbol{T}_{\boldsymbol{p}}\left({ }^{\circ} \mathbf{C}\right)$ & $\boldsymbol{T}_{\boldsymbol{c}}\left({ }^{\circ} \mathbf{C}\right)$ & $\boldsymbol{\Delta} \boldsymbol{H}(\mathbf{J} / \mathbf{g})$ & $\boldsymbol{T}_{\boldsymbol{c}}-\boldsymbol{T}_{\boldsymbol{o}}\left({ }^{\circ} \mathbf{C}\right)$ \\
\hline $\mathrm{NaCl}$ coated by WMS & 55.79 & 58.26 & 63.08 & 2.770 & 7.29 \\
$\mathrm{NaCl}$ coated by NMS & 93.42 & 102.37 & 113.28 & 2.133 & 19.86 \\
$\mathrm{NaCl}$ coated by HAMS & 130.12 & 130.71 & 132.70 & 0.212 & 2.58 \\
$\mathrm{NaCl}$ coated by GRS & 155.55 & 158.65 & 161.53 & 0.539 & 5.98 \\
$\mathrm{NaCl}$ coated by XG & 150.31 & 157.55 & 163.61 & 3.305 & 13.30 \\
$\mathrm{NaCl}$ coated by GA & 57.20 & 57.90 & 60.97 & 1.301 & 3.77 \\
\hline
\end{tabular}

${ }^{a}$ WMS-waxy maize starch; NMS-normal maize starch; HAMS-HYLON VII high amylose maize starch; GRS—gelatinized resistant starch; XG—xanthan gum; GA—gum arabic.

\subsubsection{Morphology of $\mathrm{NaCl}$ Microparticles}

The shape and surface morphology of the $\mathrm{NaCl}$ microparticles were obtained by SEM. Figure 4 shows that the starch-coated $\mathrm{NaCl}$ microparticles exhibit the morphology of maize starch. All of the $\mathrm{NaCl}$ microparticles had smooth surfaces. In addition, we did not obtain any exposed $\mathrm{NaCl}$ crystals. 


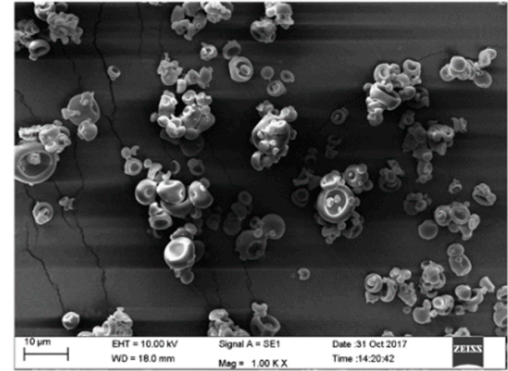

(a) $\mathrm{NaCl}$ coated by waxy maize starch

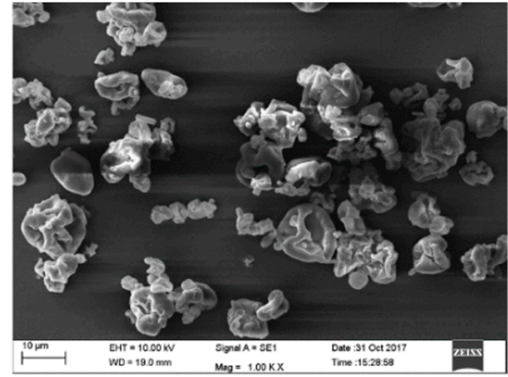

(d) $\mathrm{NaCl}$ coated by gelatinized resistant starch

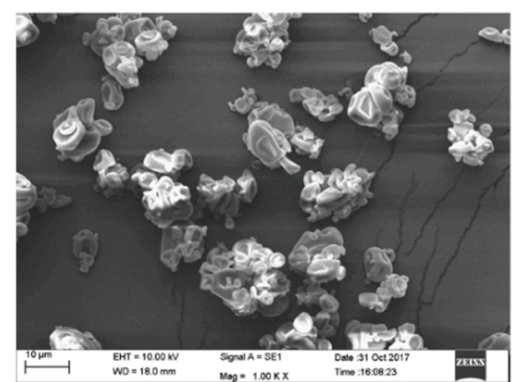

(b) $\mathrm{NaCl}$ coated by normal maize starch

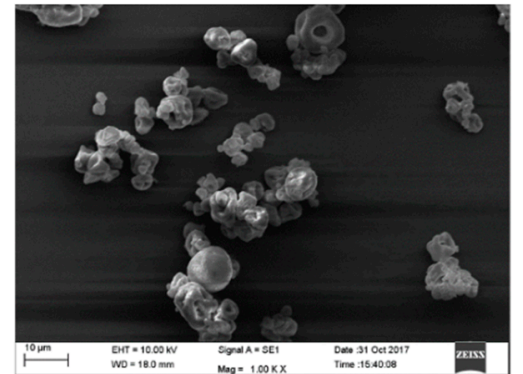

(e) $\mathrm{NaCl}$ coated by xanthan gum

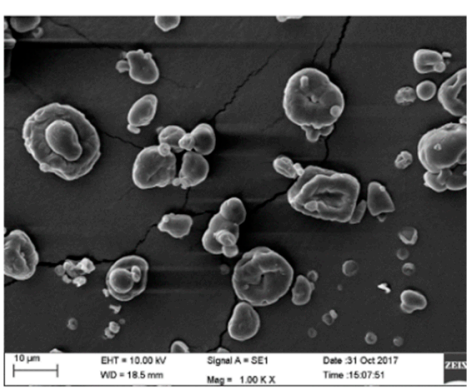

(c) $\mathrm{NaCl}$ coated by HYLON VII high amylose maize starch

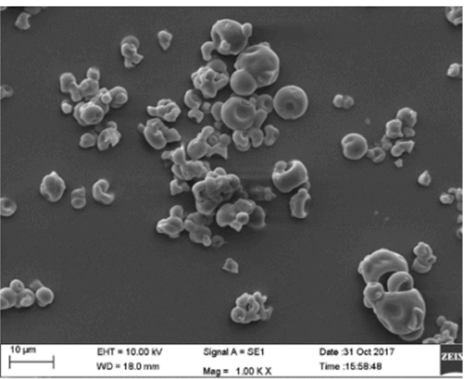

(f) $\mathrm{NaCl}$ coated by gum arabic

Figure 4. $\mathrm{NaCl}$ microparticles obtained from SEM.

From the perspective of physical chemistry, a more homogeneous structure and smooth surface of the coating material can enhance the barrier properties [57]. Therefore, it can be inferred that a more homogeneous structure and smooth surface of $\mathrm{NaCl}$ microparticles can contribute to a low release of $\mathrm{NaCl}$ from the microparticles in the solution. Water or other solvents can access the microparticle with a heterogeneous structure and roughness surface, resulting in a fast release of $\mathrm{NaCl}$.

\subsection{3. $\mathrm{NaCl}$ Release from Microparticles}

The barrier ability of the coating material to isolate $\mathrm{NaCl}$ from water was measured by the conductimetry. The release of $\mathrm{NaCl}$ was monitored over time by plotting the increase of water conductivity after the dispersion of microparticles in water (Figure 5). Compared with deionized water, no significant fluctuations in water conductivity were obtained with blank microparticles made of the coating material (data not shown). This result suggests that the coating materials do not lead to a $\mathrm{NaCl}$ release in the aqueous solution. In addition, the release rates of $\mathrm{NaCl}$ from the microparticles decreased in the following order: GA-coated $\mathrm{NaCl}>$ XG-coated $\mathrm{NaCl}>$ WMS-coated $\mathrm{NaCl}>$ NMS-coated $\mathrm{NaCl}>$ HAMS-coated $\mathrm{NaCl}>$ GRS-coated $\mathrm{NaCl}$. It can be proposed that a slow $\mathrm{NaCl}$ release from the microparticles may delay the participation of $\mathrm{NaCl}$ in $\mathrm{MR}$, thereby affecting the 3-DG and pyrraline formation. 


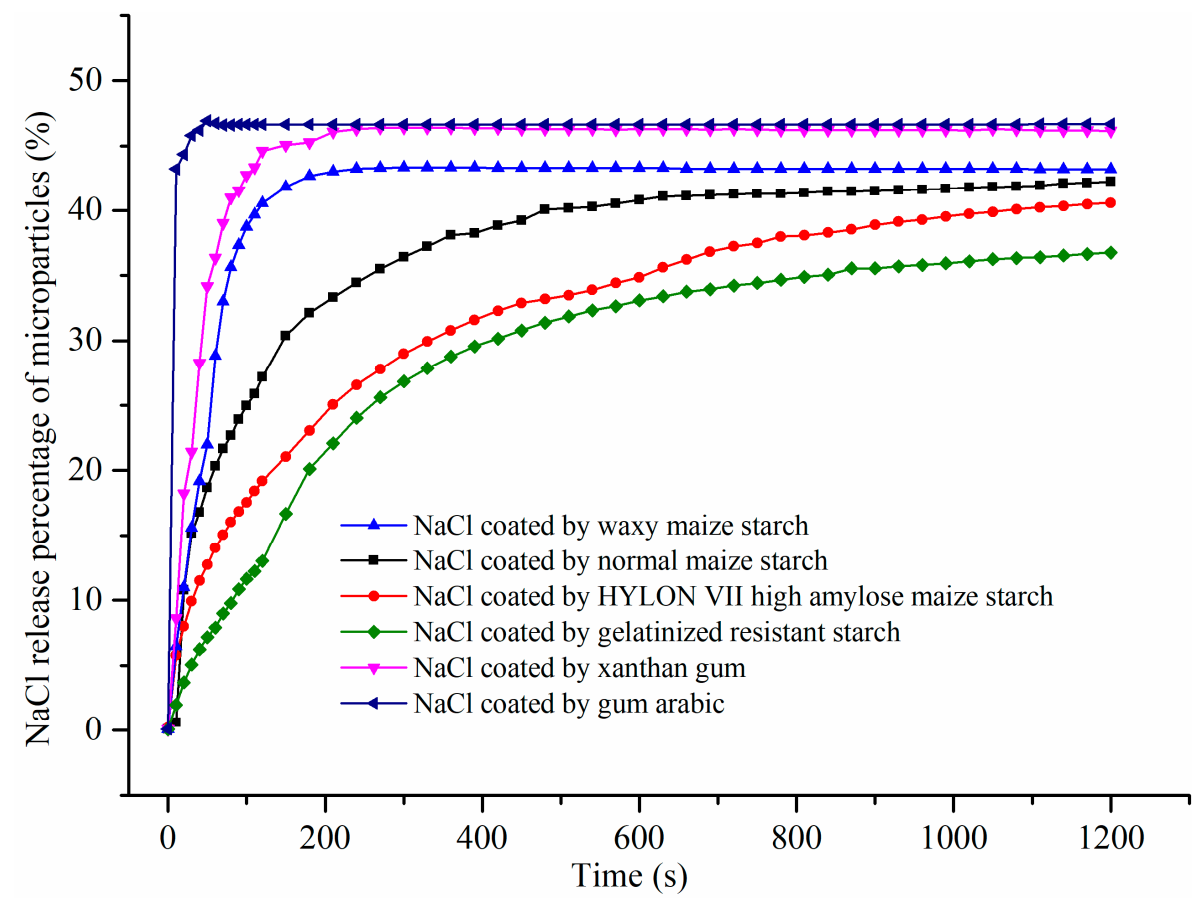

Figure 5. $\mathrm{NaCl}$ cumulative release profiles in deionized water.

However, the results of the $\mathrm{NaCl}$ release were not consistent with the transition temperatures obtained from DSC. In general, a high release rate of $\mathrm{NaCl}$ can be observed from starch-coated microparticles with low transition temperatures. However, the XG-coated $\mathrm{NaCl}$ with high transition temperatures had a high release rate of $\mathrm{NaCl}$. The transition temperatures of the GA-coated $\mathrm{NaCl}$ were approximately equal to those of the WMS-coated $\mathrm{NaCl}$, whereas the former had a higher release rate of $\mathrm{NaCl}$ compared with the latter. The inconsistency of the gum-coated microparticles may be caused by their high solubility in an aqueous solution. GA and XG can readily dissolve in water at low temperatures (below $60^{\circ} \mathrm{C}$ ) [55,56], while starches usually dissolve in water after gelatinization with heat treatment [58]. The high solubility of GA and XG can lead to a rapid disintegration of the the coating material and a rapid release of $\mathrm{NaCl}$ from the gum-coated microparticles.

\subsubsection{Browning Extent and Pyrraline Formation with the Addition of $\mathrm{NaCl}$ Microparticles}

The effect of $\mathrm{NaCl}$ encapsulation on the Maillard browning is presented in Figure $6 . \mathrm{NaCl}$ mixed with blank microparticles and $\mathrm{NaCl}$-coated microparticles significantly accelerated the extent of the browning ( five times as high as that without $\mathrm{NaCl}$ ). These results were consistent with the results presented in Figure 3. The findings confirmed that $\mathrm{MR}$ can be accelerated by $\mathrm{NaCl}$. However, there was no significant difference in the extent of browning between $\mathrm{NaCl}$ mixed with blank microparticles and $\mathrm{NaCl}$-coated microparticles. In addition, no significant difference in the extent of the browning was obtained among the groups. This finding was unexpected, and suggests that $\mathrm{NaCl}$ encapsulation has no impact on the browning, at least after the completion of MR. Furthermore, the findings indicate that $\mathrm{NaCl}$ is fully released from the microparticles following heat treatment. 


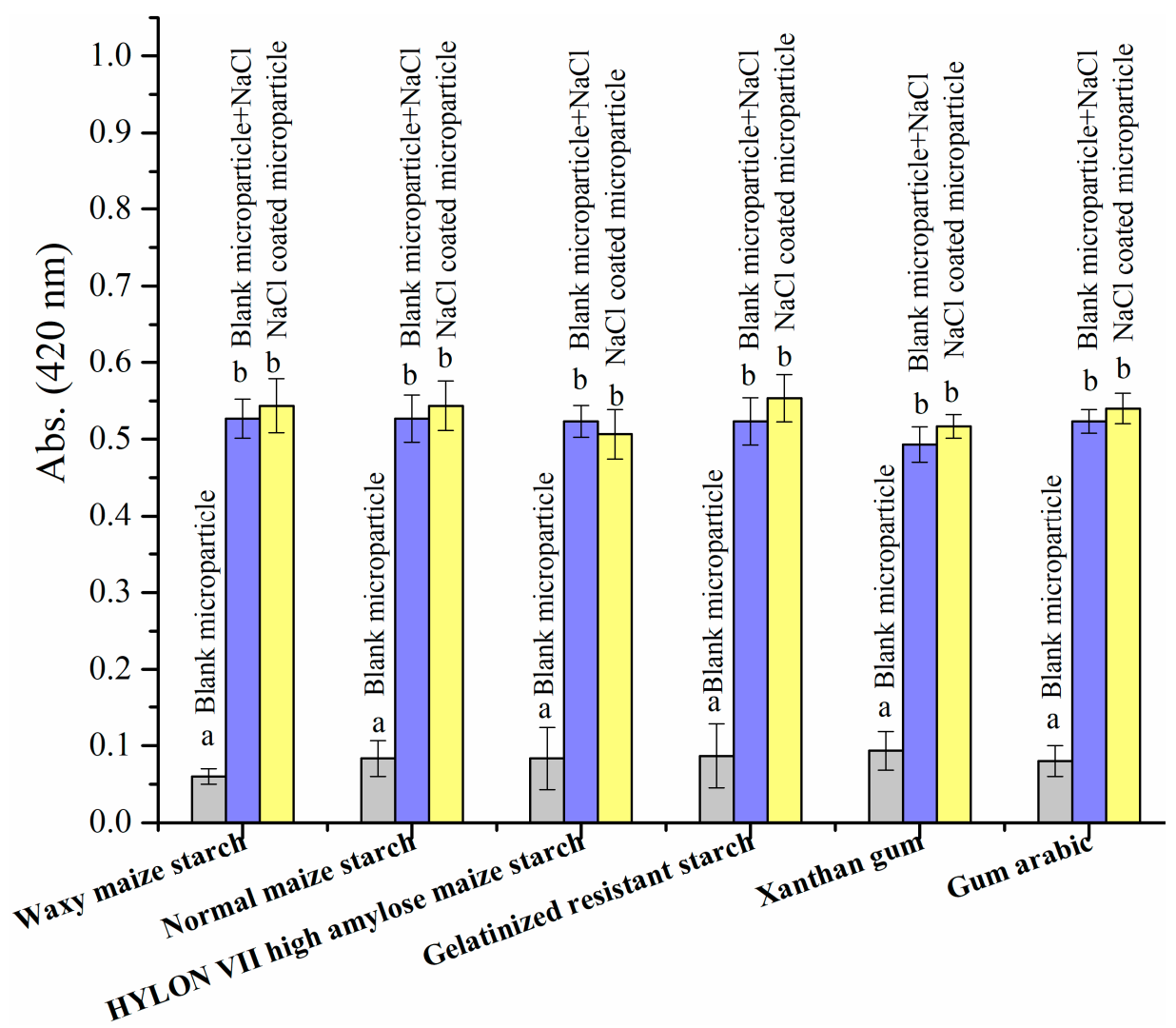

Figure 6. Extent of browning (absorbance at $420 \mathrm{~nm}$ ) in the model systems prepared with different formulations (refer to Table 1 for the formulations). Values with the same letter within a column are not significantly different ( $p>0.05$, Duncan's test).

Figure 7 shows the pyrraline formation in different model systems. In each group, $\mathrm{NaCl}$ significantly promoted pyrraline formation. However, starch-coated $\mathrm{NaCl}$ retarded the pyrraline formation when compared to $\mathrm{NaCl}$ mixed with blank microparticles. The inhibition of pyrraline formation by $\mathrm{NaCl}$-coated microparticles exhibited the following order: WMS-coated $\mathrm{NaCl}(5.1 \%)<$ NMS-coated $\mathrm{NaCl}(12.4 \%)<$ HAMS-coated $\mathrm{NaCl}(21.2 \%)<$ GRS-coated $\mathrm{NaCl}(23.5 \%)$. Unexpectedly, in the gum-coated $\mathrm{NaCl}$, we obtained no significant differences in the pyrraline concentration between the $\mathrm{NaCl}$ mixed with blank microparticles and the $\mathrm{NaCl}$-coated microparticles. These findings indicate that starch-coated microparticles with high transition temperatures reduce pyrraline formation, whereas gum-coated microparticles have little effect. The high transition temperatures of starch can be attributed to the high amylose and low amylopectin contents. These molecules with a high heat resistance may delay the $\mathrm{NaCl}$ release to the reaction solution, thereby affecting the pyrraline formation. Even though XG has a high heat resistance and GA has a heat resistance close to WMS, their high solubility weakens their barrier ability between $\mathrm{NaCl}$ and the reaction solution. In summary, the delay of $\mathrm{NaCl}$ release to the reaction solution can reduce the pyrraline formation in MR, with little effects on the browning. 


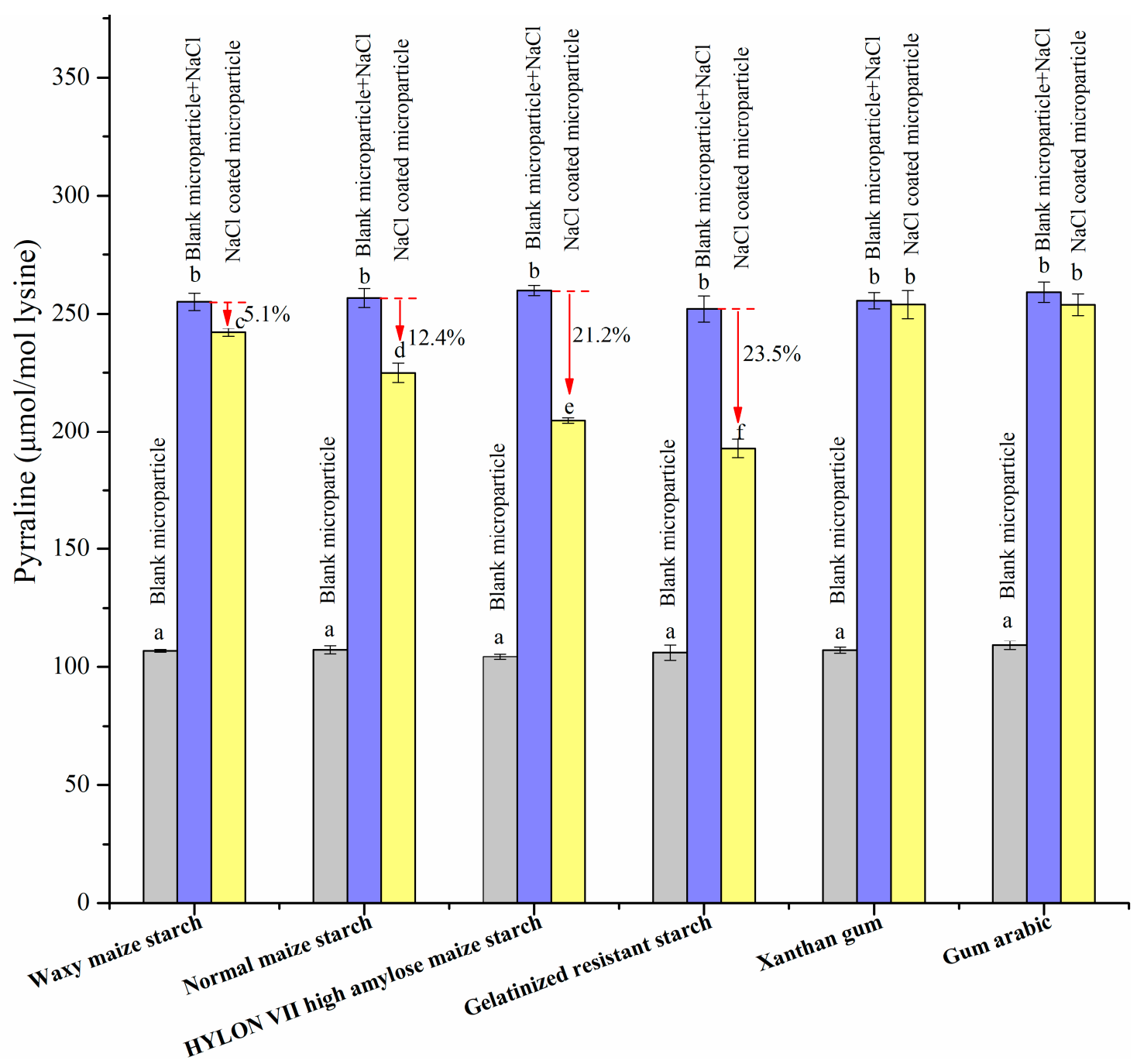

Figure 7. Concentration of pyrraline ( $\mu \mathrm{mol} / \mathrm{mol}$ lysine) in model systems prepared with different formulations (refer to Table 1 for the formulations). Values with the same letter within a column are not significantly different ( $p>0.05$, Duncan's test).

\subsubsection{3-DG Formation with the Addition of $\mathrm{NaCl}$ Microparticles}

The key intermediate of pyrraline formation, 3-DG, was monitored so as to better understand the effect of $\mathrm{NaCl}$ encapsulation on pyrraline formation in $\mathrm{MR}$. Figure 8 shows that $\mathrm{NaCl}$ mixed with blank microparticles and $\mathrm{NaCl}$-coated microparticles significantly promoted 3-DG formation. The blockage of NaCl-coated microparticles on 3-DG formation can be compared in the following order: WMS-coated $\mathrm{NaCl}(5.9 \%)<$ NMS-coated $\mathrm{NaCl}(10.8 \%)<$ HAMS-coated $\mathrm{NaCl}(22.7 \%)<$ GRS-coated $\mathrm{NaCl}(27.7 \%)$. This trend is similar to the trend obtained in pyrraline. These results indicate that starch-coated $\mathrm{NaCl}$ microparticles with a high heat resistance may weaken the 3-DG formation, because of the delay of $\mathrm{NaCl}$ release to the reaction solution. Moreover, similar to the results of pyrraline, the gum-coated $\mathrm{NaCl}$ microparticles with a high solubility limit the decrease in 3-DG formation.

Consequently, it can be proposed that the pyrraline formation prevented by the $\mathrm{NaCl}$ encapsulation stems from the effect of $\mathrm{NaCl}$ encapsulation via 3-DG formation. As previously mentioned, in the intermediate stage of MR, the 1,2-dehydration reactions of open D-glucose to dicarbonyl compounds, and the 1,2-dehydration reactions of $\beta$-D-glucose to cyclic enols can be catalyzed in the presence of $\mathrm{Na}^{+}$[48]. The former plays a major role in 3-DG formation. Therefore, the delay in the $\mathrm{NaCl}$ release may modulate the 1, 2-dehydration reactions of glucose to dicarbonyl compounds and cyclic enols, thereby affecting 3-DG formation. Future studies should investigate this proposed mechanism. 


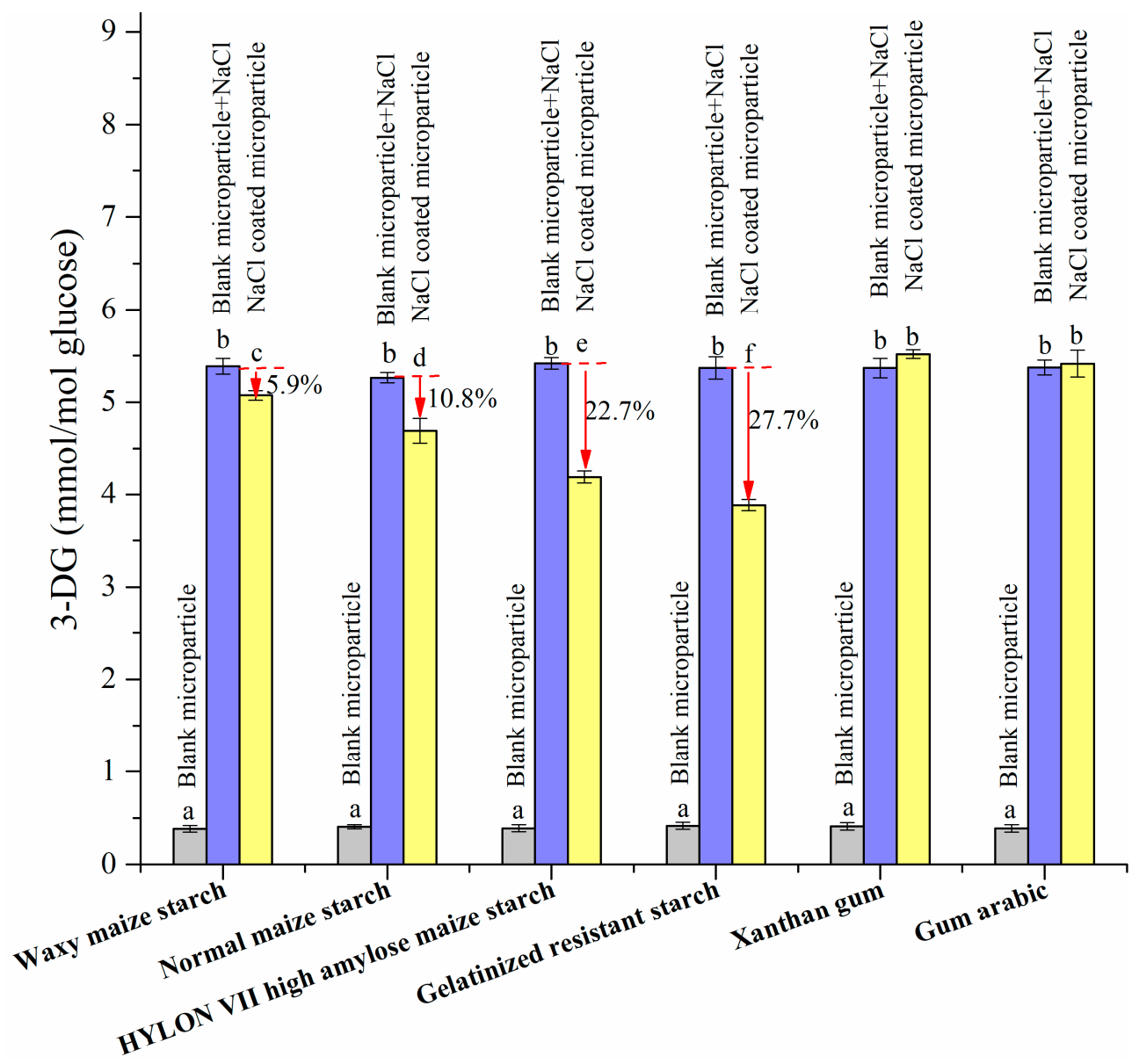

Figure 8. Concentration of 3-DG (mmol/mol glucose) in model systems prepared with different formulations (refer to Table 1 for the formulations). Values with the same letter within a column are not significantly different ( $p>0.05$, Duncan's test).

\section{Conclusions}

In $\mathrm{MR}, \mathrm{NaCl}$ significantly increased the browning intensity and pyrraline formation, with a rapid increase in 3-DG concentration. $\mathrm{NaCl}$ encapsulation is an effective strategy to mitigate pyrraline formation. NaCl-coated microparticles with a high heat resistance may prevent pyrraline via 3-DG, whereas the high solubility of the coating material offsets the effect of $\mathrm{NaCl}$ encapsulation. However, $\mathrm{NaCl}$ encapsulation has little impact on the browning intensity. The transition temperature and solubility of the coating material are the key factors that affect pyrraline formation. Encapsulation may delay the $\mathrm{NaCl}$ participation in $\mathrm{MR}$, particularly during the initial and intermediate stages.

Supplementary Materials: The following are available online at http://www.mdpi.com/2218-273X/9/11/721/s1: Figure S1: Browning development with 0.00 to $1.00 \%$ sodium in glucose-lysine-NaCl model systems; Figure S2: Browning development from 5 to $20 \mathrm{~min}$ in glucose-lysine- $\mathrm{NaCl}$ model systems; Figure S3: Thermograms (DSC) of $\mathrm{NaCl}$ encapsulated microparticles (waxy maize starch coating); Figure S4: Thermograms (DSC) of $\mathrm{NaCl}$ encapsulated microparticles (normal maize starch coating); Figure S5: Thermograms (DSC) of NaCl encapsulated microparticles (HYLON VII high amylose maize starch coating coating); Figure S6: Thermograms (DSC) of $\mathrm{NaCl}$ encapsulated microparticles (gelatinized resistant starch starch coating); Figure S7: Thermograms (DSC) of $\mathrm{NaCl}$ encapsulated microparticles (xanthan gum coating); Figure S8: Thermograms (DSC) of NaCl encapsulated microparticles (gum arabic coating).

Author Contributions: Z.L. proposed the project and wrote the manuscript. X.C. performed the research and analyzed the data about starch and gum, Z.Y. performed the ICP-OES and analyzed the data on the NaCl release. Y.L., Y.Y., C.L., and Y.Z. completed the remainder of the experiments. All of the authors read and approved the manuscript. 
Funding: The authors are grateful for the financial support from the National Natural Science Foundation of China (no. 31801667); the Guangdong Natural Science Foundation (no. 2017A030310633); the Foundation for Young Talents in Higher Education of Guangdong, China (2017KQNCX192); the Special Funds for Research Start-up of DGUT, China (GC300502-37); Funding from Institute of Science and Technology Innovation of DGUT, China (KCYCXPT2017007); and Natural Science Foundation of Guangdong Food and Drug Vocational College (No. 2016YZ006).

Conflicts of Interest: The authors declare no conflict of interest.

\section{Abbreviations}

AGEs-advanced glycation end products; d-AGEs-dietary AGEs; MR-Maillard reaction; $\mathrm{CML}^{-} \mathrm{N}^{\varepsilon}$ carboxymethyllysine; CEL- $\mathrm{N}^{\varepsilon}$-carboxyethyllysine; HMF-hydroxymethylfurfural; 1-DG-1-deoxyglucosone; 3-DG-3-deoxyglucosone; WMS — waxy maize starch; NMS—normal maize starch; HAMS—HYLON VII high amylose maize starch; GRS—gelatinized resistant starch; XG—xanthan gum; GA—gum arabic.

\section{References}

1. Nursten, H.E. The Maillard Reaction: Chemistry, Biochemistry, and Implications; Royal Society of Chemistry: Cambridge, UK, 2005.

2. Yan, S.F.; Ramasamy, R.; Schmidt, A.M. Mechanisms of Disease: Advanced glycation end-products and their receptor in inflammation and diabetes complications. Nat. Clin. Pract. Endocrinol. Metab. 2008, 4, 285. [CrossRef]

3. Milne, R.; Brownstein, S. Advanced glycation end products and diabetic retinopathy. Amino Acids 2013, 44, 1397-1407. [CrossRef] [PubMed]

4. Busch, M.; Franke, S.; Rüster, C.; Wolf, G. Advanced glycation end-products and the kidney. Eur. J. Clin. Investig. 2010, 40, 742-755. [CrossRef] [PubMed]

5. Mallipattu, S.K.; Uribarri, J. Advanced glycation end product accumulation: A new enemy to target in chronic kidney disease? Curr. Opin. Nephrol. Hypertens. 2014, 23, 547-554. [CrossRef] [PubMed]

6. Rabbani, N.; Thornalley, P.J. Advanced glycation end products in the pathogenesis of chronic kidney disease. Kidney Int. 2018, 93, 803-813. [CrossRef]

7. Uribarri, J.; del Castillo, M.D.; de la Maza, M.P.; Filip, R.; Gugliucci, A.; Luevano-Contreras, C.; Macías-Cervantes, M.H.; Markowicz Bastos, D.H.; Medrano, A.; Menini, T.; et al. Dietary advanced glycation end products and their role in health and disease. Adv. Nutr. 2015, 6, 461-473. [CrossRef]

8. Yamagishi, S.-I.; Matsui, T. Pathologic role of dietary advanced glycation end products in cardiometabolic disorders, and therapeutic intervention. Nutrition 2016, 32, 157-165. [CrossRef]

9. Luévano-Contreras, C.; Gómez-Ojeda, A.; Macías-Cervantes, M.H.; Garay-Sevilla, M.E. Dietary Advanced Glycation End Products and Cardiometabolic Risk. Curr. Diabetes Rep. 2017, 17, 63. [CrossRef]

10. Luevano-Contreras, C.; Chapman-Novakofski, K. Dietary Advanced Glycation End Products and Aging. Nutrients 2010, 2, 1247-1265. [CrossRef]

11. Clarke, R.E.; Dordevic, A.L.; Tan, S.M.; Ryan, L.; Coughlan, M.T. Dietary Advanced Glycation End Products and Risk Factors for Chronic Disease: A Systematic Review of Randomised Controlled Trials. Nutrients 2016, 8, 125. [CrossRef]

12. Gugliucci, A.; Kotani, K.; Taing, J.; Matsuoka, Y.; Sano, Y.; Yoshimura, M.; Egawa, K.; Horikawa, C.; Kitagawa, Y.; Kiso, Y.; et al. Short-Term Low Calorie Diet Intervention Reduces Serum Advanced Glycation End Products in Healthy Overweight or Obese Adults. Ann. Nutr. Metab. 2009, 54, 197-201. [CrossRef] [PubMed]

13. Snelson, M.; Clarke, R.E.; Coughlan, M.T. Stirring the Pot: Can Dietary Modification Alleviate the Burden of CKD? Nutrients 2017, 9, 265. [CrossRef] [PubMed]

14. Hellwig, M.; Witte, S.; Henle, T. Free and Protein-Bound Maillard Reaction Products in Beer: Method Development and a Survey of Different Beer Types. J. Agric. Food Chem. 2016, 64, 7234-7243. [CrossRef] [PubMed]

15. Hellwig, M.; Gensberger-Reigl, S.; Henle, T.; Pischetsrieder, M. Food-derived 1,2-dicarbonyl compounds and their role in diseases. Semin. Cancer Biol. 2018, 49, 1-8. [CrossRef] [PubMed]

16. Zhu, Y.; Snooks, H.; Sang, S. Complexity of Advanced Glycation End Products in Foods: Where Are We Now? J. Agric. Food Chem. 2018, 66, 1325-1329. [CrossRef] [PubMed] 
17. Wellner, A.; Huettl, C.; Henle, T. Formation of Maillard Reaction Products during Heat Treatment of Carrots. J. Agric. Food Chem. 2011, 59, 7992-7998. [CrossRef] [PubMed]

18. Resmini, P.; Pellegrino, L. Occurrence of protein-bound lysylpyrrolaldehyde in dried pasta. Cereal Chem. 1994, 71, 254-262.

19. Li, H.; Yu, S.-J. Review of pentosidine and pyrraline in food and chemical models: Formation, potential risks and determination. J. Sci. Food Agric. 2018, 98, 3225-3233. [CrossRef]

20. Gökmen, V.; Şenyuva, H.Z. Effects of some cations on the formation of acrylamide and furfurals in glucose-asparagine model system. Eur. Food Res. Technol. 2007, 225, 815-820. [CrossRef]

21. Levine, R.A.; Ryan, S.M. Determining the Effect of Calcium Cations on Acrylamide Formation in Cooked Wheat Products Using a Model System. J. Agric. Food Chem. 2009, 57, 6823-6829. [CrossRef]

22. Claus, A.; Mongili, M.; Weisz, G.; Schieber, A.; Carle, R. Impact of formulation and technological factors on the acrylamide content of wheat bread and bread rolls. J. Cereal Sci. 2008, 47, 546-554. [CrossRef]

23. Fiore, A.; Troise, A.D.; Ataç Mogol, B.; Roullier, V.; Gourdon, A.; El Mafadi Jian, S.; Hamzalıŏlu, B.A.; Gökmen, V.; Fogliano, V. Controlling the Maillard Reaction by Reactant Encapsulation: Sodium Chloride in Cookies. J. Agric. Food Chem. 2012, 60, 10808-10814. [CrossRef] [PubMed]

24. Dötsch, M.; Busch, J.; Batenburg, M.; Liem, G.; Tareilus, E.; Mueller, R.; Meijer, G. Strategies to Reduce Sodium Consumption: A Food Industry Perspective. Crit. Rev. Food Sci. Nutr. 2009, 49, 841-851. [CrossRef] [PubMed]

25. Koszucka, A.; Nowak, A. Thermal processing food-related toxicants: A review. Crit. Rev. Food Sci. Nutr. 2018, 1-18. [CrossRef]

26. Li, L.; Han, L.; Fu, Q.; Li, Y.; Liang, Z.; Su, J.; Li, B. Formation and Inhibition of Ne-(Carboxymethyl)lysine in Saccharide-Lysine Model Systems during Microwave Heating. Molecules 2012, 17, 12758-12770. [CrossRef]

27. Liang, Z.; Li, L.; Fu, Q.; Zhang, X.; Xu, Z.; Li, B. Formation and elimination of pyrraline in the Maillard reaction in a saccharide-lysine model system. J. Sci. Food Agric. 2016, 96, 2555-2564. [CrossRef]

28. Liang, Z.; Li, L.; Qi, H.; Zhang, Z.X.X.; Li, B. Kinetic Study on Peptide-Bound Pyrraline Formation and Elimination in the Maillard Reaction Using Single- and Multiple-Response Models. J. Food Sci. 2016, 81, C2405-C2424. [CrossRef]

29. Lee, A.K.; Schieb, L.J.; Yuan, K.; Maalouf, J.; Gillespie, C.; Cogswell, M.E. Sodium content in packaged foods by census division in the United States, 2009. Prev. Chronic Dis. 2015, 12, E43. [CrossRef]

30. Eyles, H.; Shields, E.; Webster, J.; Ni Mhurchu, C. Achieving the WHO sodium target: Estimation of reductions required in the sodium content of packaged foods and other sources of dietary sodium. Am. J. Clin. Nutr. 2016, 104, 470-479. [CrossRef]

31. Wolfson, J.A.; Moran, A.J.; Jarlenski, M.P.; Bleich, S.N. Trends in Sodium Content of Menu Items in Large Chain Restaurants in the U.S. Am. J. Prev. Med. 2018, 54, 28-36. [CrossRef]

32. Dunford, E.K.; Ni Mhurchu, C.; Huang, L.; Vandevijvere, S.; Swinburn, B.; Pravst, I.; Tolentino-Mayo, L.; Reyes, M.; L'Abbe, M.; Neal, B.C. A comparison of the healthiness of packaged foods and beverages from 12 countries using the Health Star Rating nutrient profiling system, 2013-2018. Obes. Rev. 2019, 1-9. [CrossRef] [PubMed]

33. Ahuja, J.K.C.; Li, Y.; Haytowitz, D.B.; Bahadur, R.; Pehrsson, P.R.; Cogswell, M.E. Assessing Changes in Sodium Content of Selected Popular Commercially Processed and Restaurant Foods: Results from the USDA: CDC Sentinel Foods Surveillance Program. Nutrients 2019, 11, 1754. [CrossRef] [PubMed]

34. Saltmarch, M.; Labuza, T.P. Nonenzymatic Browning via the Maillard Reaction in Foods. Diabetes 1982, 31, 29-36. [CrossRef]

35. Kwak, E.-J.; Lim, S.-I. The effect of sugar, amino acid, metal ion, and $\mathrm{NaCl}$ on model Maillard reaction under pH control. Amino Acids 2004, 27, 85-90. [CrossRef] [PubMed]

36. Moreau, L.; Bindzus, W.; Hill, S. Influence of Sodium Chloride on Color Development of Cereal Model Systems Through Changes in Glass Transition Temperature and Water Retention. Cereal Chem. 2009, 86, 232-238. [CrossRef]

37. Moreau, L.; Lagrange, J.; Bindzus, W.; Hill, S. Influence of sodium chloride on colour, residual volatiles and acrylamide formation in model systems and breakfast cereals. Int. J. Food Sci. Technol. 2009, 44, 2407-2416. [CrossRef]

38. Rizzi, G.P. Effects of Cationic Species on Visual Color Formation in Model Maillard Reactions of Pentose Sugars and Amino Acids. J. Agric. Food Chem. 2008, 56, 7160-7164. [CrossRef] 
39. Yamaguchi, K.; Noumi, Y.; Nakajima, K.; Nagatsuka, C.; Aizawa, H.; Nakawaki, R.; Mizude, E.; Otsuka, Y.; Homma, T.; Chuyen, N.V. Effects of Salt Concentration on the Reaction Rate of Glc with Amino Acids, Peptides, and Proteins. Biosci. Biotechnol. Biochem. 2009, 73, 2379. [CrossRef]

40. Bell, L.N. Maillard reaction as influenced by buffer type and concentration. Food Chem. 1997, 59, $143-147$. [CrossRef]

41. Rizzi, G.P. Role of Phosphate and Carboxylate Ions in Maillard Browning. J. Agric. Food Chem. 2004, 52, 953-957. [CrossRef]

42. Kocadağlı, T.; Gökmen, V. Effects of Sodium Chloride, Potassium Chloride, and Calcium Chloride on the Formation of $\alpha$-Dicarbonyl Compounds and Furfurals and the Development of Browning in Cookies during Baking. J. Agric. Food Chem. 2016, 64, 7838-7848. [CrossRef] [PubMed]

43. Levine, R.A.; Smith, R.E. Sources of Variability of Acrylamide Levels in a Cracker Model. J. Agric. Food Chem. 2005, 53, 4410-4416. [CrossRef] [PubMed]

44. Portero-Otin, M.; Nagaraj, R.H.; Monnier, V.M. Chromatographic evidence for pyrraline formation during protein glycation in vitro and in vivo. Biochim. Et Biophys. Acta (Bba)-Protein Struct. Mol. Enzymol. 1995, 1247, 74-80. [CrossRef]

45. Hodge, J.E. Dehydrated Foods, Chemistry of Browning Reactions in Model Systems. J. Agric. Food Chem. 1953, 1, 928-943. [CrossRef]

46. Kocadağl1, T.; Gökmen, V. Effect of Sodium Chloride on $\alpha$-Dicarbonyl Compound and 5-Hydroxymethyl2-furfural Formations from Glucose under Caramelization Conditions: A Multiresponse Kinetic Modeling Approach. J. Agric. Food Chem. 2016, 64, 6333-6342. [CrossRef]

47. Zhao, H.; Holladay, J.E.; Brown, H.; Zhang, Z.C. Metal Chlorides in Ionic Liquid Solvents Convert Sugars to 5-Hydroxymethylfurfural. Science 2007, 316, 1597-1600. [CrossRef]

48. Mayes, H.B.; Nolte, M.W.; Beckham, G.T.; Shanks, B.H.; Broadbelt, L.J. The Alpha-Bet(a) of Salty Glucose Pyrolysis: Computational Investigations Reveal Carbohydrate Pyrolysis Catalytic Action by Sodium Ions. ACS Catal. 2015, 5, 192-202. [CrossRef]

49. Liang, Z.; Li, L.; Qi, H.; Wan, L.; Cai, P.; Xu, Z.; Li, B. Formation of Peptide Bound Pyrraline in the Maillard Model Systems with Different Lys-Containing Dipeptides and Tripeptides. Molecules 2016, 21, 463. [CrossRef]

50. Saddawi, A.; Jones, J.M.; Williams, A. Influence of alkali metals on the kinetics of the thermal decomposition of biomass. Fuel Process. Technol. 2012, 104, 189-197. [CrossRef]

51. Mayes, H.B.; Tian, J.; Nolte, M.W.; Shanks, B.H.; Beckham, G.T.; Gnanakaran, S.; Broadbelt, L.J. Sodium Ion Interactions with Aqueous Glucose: Insights from Quantum Mechanics, Molecular Dynamics, and Experiment. J. Phys. Chem. B 2014, 118, 1990-2000. [CrossRef]

52. Lutz, R.; Aserin, A.; Wicker, L.; Garti, N. Release of electrolytes from W/O/W double emulsions stabilized by a soluble complex of modified pectin and whey protein isolate. Colloids Surf. B: Biointerfaces 2009, 74, 178-185. [CrossRef] [PubMed]

53. Sapei, L.; Naqvi, M.A.; Rousseau, D. Stability and release properties of double emulsions for food applications. Food Hydrocoll. 2012, 27, 316-323. [CrossRef]

54. Chen, X.; He, X.-W.; Zhang, B.; Fu, X.; Jane, J.-L.; Huang, Q. Effects of adding corn oil and soy protein to corn starch on the physicochemical and digestive properties of the starch. Int. J. Biol. Macromol. 2017, 104, 481-486. [CrossRef] [PubMed]

55. Sworn, G. 8-Xanthan gum. In Handbook of Hydrocolloids, 2nd ed.; Phillips, G.O., Williams, P.A., Eds.; Woodhead Publishing: Boca Raton, FL, USA, 2009; pp. 186-203.

56. Williams, P.A.; Phillips, G.O. 11-Gum arabic. In Handbook of Hydrocolloids, 2nd ed.; Phillips, G.O., Williams, P.A., Eds.; Woodhead Publishing: Boca Raton, FL, USA, 2009; pp. 252-273.

57. Venugopal, V. Edible Films and Carrier Matrices from Marine Polysaccharides. In Marine Polysaccharides: Food Applications; Venugopal, V., Ed.; CRC press: Boca Raton, FL, USA; pp. 291-293.

58. Zobel, H.F. CHAPTER IX-Gelatinization of starch and mechanical properties of starch pastes. In Starch: Chemistry and Technology, 2nd ed.; Whistler, R.L., Bemiller, J.N., Paschall, E.F., Eds.; Academic Press: San Diego, CA, USA, 1984; pp. 285-309.

(C) 2019 by the authors. Licensee MDPI, Basel, Switzerland. This article is an open access article distributed under the terms and conditions of the Creative Commons Attribution (CC BY) license (http://creativecommons.org/licenses/by/4.0/). 